\title{
NOTAS ACERCA DEL ORIGEN Y TRAYECTORIA DEL DERECHO CONSTITUCIONAL A LA PROTECCIÓN A LA SALUD EN CHILE ${ }^{1}$
}

\author{
JAVIER COUSO* \\ MAURICIO REYES ${ }^{* *}$
}

RESUMEN: El trabajo aborda los orígenes y trayectoria del derecho constitucional a la protección de la salud en Chile, desde el siglo diecinueve hasta nuestros días, pasando revista a los diferentes hitos que fueron configurando su reconocimiento constitucional, su desarrollo legislativo y el tratamiento jurisprudencial que ha tenido.

PALABRAS CLAVE: derecho a la salud - protección constitucional de la salud - regulación legal del derecho a la salud - historia del derecho a la salud en Chile.

\section{ORIGIN AND TRAJECTORY OF THE CONSTITUTIONAL RIGHT TO PROTECTION OF HEALTHCARE IN CHILE}

ABSTRACT: This work analyses the origins and trajectory of the right to health care in Chile, from the nineteenth century to date, going through the critical junctures that helped shape the constitutional recognition and legislative treatment and development of this right.

KEY WORDS: Right to healthcare - protective duties of healthcare regulation of the right to healthcare - history of the right to healthcare in Chile.

Abogado, M.A. y Ph.D. en Jurisprudence and Social Policy, por la Universidad de California Berkeley (EE.UU.). Profesor Titular de Derecho Constitucional, Facultad de Derecho de la Universidad Diego Portales. Correo electrónico: javier.couso@udp.cl

. Abogado. Profesor ayudante del Departamento de Derecho Público de la facultad de Derecho de la Universidad Diego Portales, abogado del Ministerio del Interior. Correo electrónico: mauricioreyesopazo@hotmail.com

1 El presente artículo se enmarca en la ejecución del Proyecto FONDECYT No 1060255 "Comunidad e igualdad: lo que nos debemos recíprocamente" en donde Javier Couso actúa como coinvestigador.

Fecha de recepción: 30 de noviembre de 2009.

Fecha de aprobación: 18 de diciembre de 2009. 


\section{INTRODUCCIÓN}

Como ocurre en muchos países, el ordenamiento constitucional chileno reconoce el derecho a la salud (o "a la protección de la salud", como reza el artículo 19 número 9 de nuestra Carta Fundamental). Esto ha sido así desde comienzos del siglo XX, a partir de la Constitución de 1925, por lo que el reconocimiento de este derecho representa a estas alturas una verdadera tradición constitucional. Dicho esto, falta información acerca de los orígenes y trayectoria de este derecho fundamental que -de un tiempo a esta parte- ha cobrado extraordinaria significación a partir de resoluciones judiciales que lo utilizan como fundamento para acoger acciones de inaplicabilidades y recursos de protección. En este trabajo, se busca paliar en parte este déficit, para lo cual se describen y analizan los orígenes históricos e hitos más relevantes del reconocimiento del derecho a la salud en nuestro país, en sus dimensiones constitucionales y legales.

\section{1) Regulación del derecho a la salud en Chile. Aspectos HISTÓRICOS}

\section{(1.1) ANTECEDENTES PREVIOS. LEGISLACIÓN SANITARIA}

La configuración del derecho a la salud en Chile, su establecimiento y regulación constitucional, legal y administrativa, son un fenómeno del siglo XX, aun cuando ya el propio Pedro de Valdivia se manifestara preocupado por asuntos sanitarios ${ }^{2}$. En la era colonial, el sistema sanitario del país (hospitales y hospicios) estuvo entregado a la supervisión directa de "los Cabildos y [por] los obispos, cuyas intervenciones eran esporádicas" ${ }^{3}$. El financiamiento de estos establecimientos -más allá de la ayuda que recibían del Cabildo y de las comunidades religiosas- provenía en gran parte de donaciones y ayudas que las familias prósperas realizaban, motivadas por el concepto cristiano de caridad ${ }^{4}$. En todo caso, dada

2 Pedro de Valdivia, en 1552, fundó en Santiago el primer hospital, el que fue posteriormente entregado a la Congregación de los Hermanos de San Juan de Dios, que le dieron su nombre. Este centro asistencial estuvo dotado de 50 camas y destinado a la atención de los menesterosos, Miranda R., Ernesto (1990). "Descentralización y privatización del sistema de salud”, Estudios Públicos, No 39, pp. 5-66. [Disponible en línea: www.cepchile.cl Fecha de visita 16 de julio de 2009], p. 8.

Miranda (1990) 8.

La expresión 'caridad', que en el cristianismo es una de las tres virtudes teologales, consiste en amar a Dios sobre todas las cosas, y al prójimo como a nosotros mismos. Sin embargo, por mucho tiempo, se le vinculó casi exclusivamente con la limosna, o se le entregó un papel de "rellenar [los] vacíos que suele dejar inconcluso la mejor de las institucionalidades". Villegas, Beltrán (ss.cc) (2001). "La caridad y el otro como otro". Estudios Públicos, No 81, pp. 81-88. [Disponible en línea: www.cepchile.cl Fecha de visita 24 de septiembre de 2009], p. 81. 
la pobre base científica y tecnológica de los tratamientos y prestaciones médicas que se brindaban gracias a estos aportes, la era colonial estuvo marcada por altas tasas de mortalidad.

La precaria institucionalidad sanitaria erigida en la Colonia, que, como veíamos, se sostenía principalmente en la caridad, no tuvo la fuerza suficiente como para hacer frente a las enfermedades nuevas que, producto de la apertura comercial generada por el proceso de independencia, llegaron a Chile en el siglo XIX. En este contexto, las elites y los sectores bajos buscaron mediante la constitución de organizaciones de la sociedad civil resolver los problemas de salud que aquejaban a gran parte de la población.

La inexistencia de políticas de salud gubernamentales continuaría hasta entrado el siglo XIX, hasta que surgió un debate sobre el punto, caracterizado por muy disímiles concepciones e ideas acerca de la salud. Por un lado, se encontraba la visión del grupo dirigente, que planteaba que la miseria y las "epidemias... diezman a nuestra población, [se] lleván[dose] miles de brazos de valor inestimable para el progreso y la riqueza del país" 5 . De acuerdo a esta forma de ver el desafío sanitario, enfermedad y muerte equivalían a una disminución de la producción. Esto llevó a miembros de la elite a financiar la salubridad de ciudades, pueblos y villas. Por otro lado, obreros y trabajadores -que observaban con angustia cómo la enfermedad, los accidentes y la muerte impactaban sus familias y a ellos mismos ante la indiferencia de la autoridad-comenzaron a constituir sociedades de Socorros Mutuos, las que se organizaron con la finalidad de otorgar a sus miembros "solidaria protección ante la enfermedad, la muerte y el desamparo familiar" 6 .

Más adelante, la viruela y el cólera detonarían a fines del siglo XIX una decidida acción del gobierno. Así, el Estado pasó de la indiferencia respecto a estos asuntos a erigirse como la entidad rectora de la salud pública. Este cambio del rol del Estado se advierte en la discusión ocurrida en el Congreso Nacional a propósito de un proyecto de ley impulsado por el presidente Santa María, y que buscaba imponer un régimen de vacunación obligatoria que previniera y atajara la propagación de la viruela. El debate generado en la Cámara de Diputados durante la tramitación de la ley puso en evidencia dos visiones contrapuestas acerca del rol que cabía al Estado en materia de salud. Así, mientras que para algunos "la salud como política aparecía como una forma de intromisión del Estado en el individuo-patrón, en su propiedad y sus relaciones de trabajo; más aún,

\footnotetext{
5 Illanes, María Angélica (1993). En nombre del Pueblo, del Estado y de la Ciencia, (...) Historia Social de la Salud Pública Chile 1880/1973. Santiago: editado por el Colectivo de Atención Primaria, 514 pp., p. 28. ILLANES (1993) 36.
} 
hasta en la misma intimidad de su propio cuerpo y el de su familia", para otros, esta política sanitaria diseñada por el gobierno era el único remedio eficaz ante la envergadura de la emergencia generada por la viruela. Si bien esta discusión no se tradujo en la imposición de una política de vacunación para el país, en los hechos dio al presidente Santa María elementos para dictar (el 27 de enero de 1886) un decreto que reglamentó la llamada Junta de Beneficencia ${ }^{8}$, que tenía como finalidad dar unidad administrativa a todos los establecimientos de la beneficencia, entrando el Estado, "por primera vez, a fiscalizar la acción conjunta de lo privado y lo público en el ámbito de la caridad social"?.

Más allá de estos gestos iniciales, la epidemia de cólera que afectó al país en 1887 animó a la dirigencia nacional a dar un paso más en el rechazo del laissez-faire sanitario imperante, puesto que -ante la inminencia de otra emergencia sanitaria- la elite se abocó a estudiar, proponer y aprobar legislación que, por un lado, otorgó a la autoridad ejecutiva facultades suficientes para hacer frente a la epidemia y, por el otro, creó entidades capaces de proponer al gobierno medidas tendientes a evitar o prevenir este tipo de enfermedades. Producto de esta discusión, eventualmente se creó la Junta General de Salubridad, que asesoraría al gobierno en materias de salud y que sería reemplazada, en 1892, por el Consejo Superior de Higiene, introducido por un proyecto de ley del presidente Balmaceda, que fue finalmente aprobado en la administración de Jorge Montt.

Más adelante (hacia 1917), el sistema sanitario estructurado sobre la base de las Juntas de Beneficencia comenzó a presentar signos de desgaste, lo que se exteriorizó en hospitales a medio construir y en prestaciones de salud ineficientes e ineficaces. Enfrentados a esta nueva realidad, algunos líderes políticos -como el diputado Manuel Barrenechea- estimaron que "era necesario buscar una fórmula legal que pusiese de acuerdo a los principios de la ciencia, los conocimientos técnicos y la práctica en materia de beneficencia pública" ${ }^{10}$, ya que la bancarrota de la Beneficencia y los conflictos generados por la "cuestión social", podían "amenazar el orden establecido" 11 .

ILLANES (1993) 65.

8 La Junta de Beneficencia es la continuadora de la Junta Directora de Hospitales y Casas de Expósitos que fue creada en 1832 por el Gobierno del general José Joaquín Prieto, en MiRANDA (1990) 9.

ILLANES (1993) 66.

ILlanes (1993) 126.

ILLANES (1993) 126. 
Unido a lo anterior, pero sin la estridencia de los conflictos mencionados, comenzó a instalarse la idea de "la responsabilidad y el deber social del Estado", cuya manifestación más elocuente fue la modificación de la expresión "Beneficencia" por "Asistencia Social", "concepto que dejaba fuera la idea caritativa del "beneficio" y miraba más allá del indigente: visualizaba la sociedad en general" 12 . Producto de este desarrollo, el presidente Sanfuentes, ante la debacle social que podía significar la quiebra de la Beneficencia, resolvió enviar al Congreso Nacional un proyecto de ley que contemplaba un sistema de financiamiento permanente a estas instituciones, así como normas tendientes a lograr su reorganización administrativa, lo que se lograría creando un Consejo General de la Beneficencia que diera "unidad técnica a todos los hospitales del país"13, puesto que, como lo expresaba el ministro del Interior de la época, "la Beneficencia no es un acto facultativo, voluntario, sino un servicio público, una carga social a la cual el gobierno está obligado a subvenir" ${ }^{14}$, es decir, al Estado le cabía en materia de política social un rol asistencial.

Aunque la idea del Estado asistencial en materia sanitaria llegó más adelante a tener expresiones regulatorias claras (como el Código Sanitario de 1918), no fue sino hasta 1924 cuando este concepto encontró su expresión institucional más fuerte, al crearse el Ministerio de Higiene, Asistencia, Trabajo y Previsión Social.

\section{(1.2) CONSTITUCIONALIZACIÓN Y DESARROLLO DEL DERECHO A LA SALUD EN LA CARTA DE 1925}

\section{(1.2.1) El derecho a la salud en la Constitución de 1925}

Los derechos sociales y, en especial, el de protección de la salud comenzaron a ser reconocidos constitucionalmente en diversas naciones al concluir la Primera Guerra Mundial. En efecto, en esa época se desarrollaron corrientes intelectuales que propugnaban el reconocimiento de los llamados 'derechos económico-sociales' o 'derechos positivos'15. Estas ideas, que caracterizaron lo que se denominó el 'constitucionalismo social', eventualmente se vieron plasmadas en la Constitución de México (en 1917) y en la de Weimar (en 1919).

ILLANES (1993) 126.

Miranda (1990) 9.

ILLANES (1993) 127.

En Chile, uno de los primeros en comentar la emergencia de este tipo de derechos los definía así: "la inmensa mayoría de los gobernados no teme ahora la actividad del poder sino que la reclama angustiosamente cuando carece de los medios indispensables para progresar hacia una vida digna". Silva Bascuńán, Alejandro (1997). Tratado de Derecho Constitucional, Santiago: Editorial Jurídica de Chile. T. II, 271 pp., p. 219. 
En Chile, como señalábamos más arriba, desde fines del siglo XIX y principios del XX habían surgido algunas iniciativas que buscaban hacerse cargo no solo del estado sanitario de los trabajadores y la sociedad en general, sino que de proteger a los trabajadores de algunos sectores industriales ${ }^{16}$. Más allá de estas iniciativas embrionarias, la recepción normativa del constitucionalismo social llegaría a Chile con la Constitución de 1925. El antecedente de este importante cambio fue la grave crisis social y política que venía experimentando el país desde la década anterior, producto de la alicaída o nula actividad de las instituciones estatales frente a la llamada 'cuestión social'. Así las cosas, una vez producido el quiebre institucional que derribó a la república parlamentaria (1924), y convocados distintos sectores políticos a participar en el debate de una nueva Constitución, en la Comisión Constituyente a la que le correspondió el estudio de la misma se discutió por primera vez el asunto de los derechos económico-sociales ${ }^{17}$.

Del análisis de la labor de la mencionada Comisión se desprende que, aunque su trabajo se circunscribió en gran medida al examen de las instituciones políticas que debía establecer la nueva Constitución -en especial, aquellas que permitían la instauración de un régimen presidencial-, existió un importante debate respecto a los derechos de carácter económico-social. Dicho esto, debe anotarse que en relación al derecho a la salud, su tratamiento fue más bien incidental, ya que se discutió a propósito de la norma que garantizaría la protección al trabajo. En efecto, la mención que se hizo al derecho a la salud provino de una indicación realizada por el experto sanitario extranjero Dr. John D. Long ${ }^{18}$, y no como una garantía constitucional separada y que fuera objeto de un estudio especial. En todo caso, debe subrayarse que la forma tangencial en que se debatió acerca del derecho a la salud en la Comisión Constituyente de 1925 no era algo extraño en una época en que la preocupación por la salud de las personas estaba íntimamente ligada a "la recuperación de la fuerza de trabajo industrial" ${ }^{19}$. Esto sugiere que la motivación central fue

16 Así, por ejemplo, se dicta la Ley de Habitaciones Obreras, en febrero de 1906. Sin embargo, fue a partir de 1914 cuando se promulgan diversas leyes sociales, como la ley que exígía que en los establecimientos comerciales existiera un número de sillas suficientes para los empleados, la indemnización por accidentes del trabajo, la que ordenó el descanso dominical, y la que creó la Caja de Retiro y Previsión Social de los Ferrocarriles del Estado

17 La Comisión Constituyente se formó por decreto número 1.422 de abril 7 de 1925 . La Comisión se dividió en dos subcomisiones, una dedicada a preparar el proyecto de reforma y la otra a considerar la manera en que serían aprobados los cambios que se aconsejaban. La subcomisión de reforma sesionó treinta y tres sesiones.

18 John D. Long era, al momento de llegar a Chile, subdirector del Servicio Federal de Sanidad de los Estados Unidos.

19 Labra, María Eliana (2004). "Medicina Social en Chile: Propuestas y debates (19201950)". Cuadernos Médico Sociales. Vol. 44, 4, pp. 207-219. [Disponible en línea: www. colegiomedico.cl Fecha de visita 28 de febrero de 2009] p. 211. 
la protección constitucional de la salud de los trabajadores -especialmente el motor industrial de la nación-y no la de toda la población.

Así las cosas, la sugerencia de Long de introducir una norma constitucional que reconociera el derecho a la protección de la salud al alero del artículo que garantizaba el derecho al trabajo, fue acogida por la Comisión, lo que se materializó finalmente en el número 14 del artículo 10 de la Constitución de $1925^{20}$.

\section{(1.2.2) Desarrollo del derecho a la salud durante el periodo 1925- 1970}

Desde la promulgación de la Carta de 1925 (y hasta 1970) no existieron modificaciones al Texto Constitucional en materia del derecho a la salud, por lo que el desarrollo y la profundización del mismo estuvieron entregados a la legislación.

En la regulación legal de esta garantía constitucional pueden distinguirse tres etapas. En la primera -que comienza en 1925 y concluye en 1938-, se crearon instituciones sanitarias y seguros de salud dirigidos a cubrir a los obreros por las contingencias de enfermedad o invalidez. Es así como el 8 de septiembre de 1925 se introdujo el Seguro Obrero Obligatorio de Enfermedades e Invalidez, que tenía por objeto la "asistencia médica y dental para el imponente, subsidios por enfermedad, indemnizaciones por muerte y pensiones de invalidez y retiro" 21 . Estos criterios respecto al rol de salud y su protección eventualmente llevaron a la promulgación de la Ley de Medicina Preventiva (1938), cuyo objetivo central era "prevenir el desarrollo de enfermedades por medio de su pesquisa en la fase preclínica y determinar las personas que debían acogerse a reposo preventivo" 22 y en donde lo que se pretendía "[era] que el Estado, por intermedio de la medicina dirigida, actúe sobre la 'máquina' que debe ser urgentemente reparada; sobre el hombre trabajador" 23 .

Con la llegada del Frente Popular al gobierno (1938), la visión del

"Artículo 10. La Constitución asegura a todos los habitantes de la República: 14: La protección al trabajo, a la industria, y a las obras de previsión social, especialmente en cuanto se refieren a la habitación sana y a las condiciones económicas de la vida, en forma de proporcionar a cada habitante un minimo de bienestar, adecuado a la satisfacción de sus necesidades personales y a las de su familia. La ley regulará esta organización. El Estado propenderá a la conveniente división de la propiedad y a la constitución de la propiedad familiar. Ninguna clase de trabajo o industria puede ser probibida, a menos que se oponga a las buenas costumbres, a la seguridad o a la salubridad pública, o que lo exija el interés nacional y una ley lo declare asi. Es deber del Estado velar por la salud pública y el bienestar higiénico del pais. Deberá destinarse cada año una cantidad de dinero suficiente para mantener un servicio nacional de salubridad".

21 Nancuante Almonacid, Ulises y Sotomayor Klapp, Roberto (2001). Derecho de la Salud. Santiago: Editorial Jurídica ConoSur, 627 pp., p. 13.

22 NANCUANTE/ Sotomayor (2001) 13.

23 Labra (2004) 212. 
derecho a la salud y el rol que el Estado debía jugar en esta materia dio un brusco vuelco. De acuerdo al entonces ministro de Salud y Previsión Social, Salvador Allende, la legislación existente hasta el año 1938 (en particular, la Ley de Medicina Preventiva), si bien había sido beneficiosa para un grupo considerable de la población, no resolvía completamente la situación sanitaria del país ya que, de acuerdo a Allende, "son los factores sociales, económicos y ambientales los que inciden directamente en la salud" 24 , y no la enfermedad la que genera pobreza. Como consecuencia de lo anterior, continuaba Allende, el Estado debía actuar sobre todos esos factores, lo que implicaba que "no hay que escatimar medios para conjurar la amenaza a la existencia misma de la nación. Para ello, no solo las clases poseedoras deben contribuir sin regateos, sino que todos los ciudadanos deben secundar la enorme tarea de levantar económica, sanitaria y culturalmente el país" 25 . Estos conceptos se plasmaron posteriormente en un proyecto de ley de reforma social que -si bien se envió al Congreso en 1941- "durmió sin tratamiento en las comisiones parlamentarias, durante casi una década" 26 .

Años más tarde, en la década del 50, se rescataría del olvido el mencionado proyecto de 1941 y se avanzaría en la profundización del derecho a la salud. En esta discusión parlamentaria fueron fundamentales las opiniones del abogado falangista Francisco Pinto Santa Cruz y del médico Benjamín Viel, quienes defendieron el sistema de protección social de la salud instituido en Inglaterra por esos años. Los juicios y razonamiento vertidos por Pinto y Viel, así como por otros participantes en el debate parlamentario, llevaron a la creación del Servicio Nacional de Salud ${ }^{27}$ y el Servicio del Seguro Social, en $1952^{28}$.

Aun cuando se esperaba que estas instituciones se transformaran en la base a partir de la cual se desarrollaría y evolucionaría el Estado de bienestar en Chile, diferentes obstáculos lo impidieron. El Servicio Nacional de Salud, en especial, sufrió los vaivenes de "políticas contradictorias y antagónicas con su doctrina fundacional" 29 , como el que se excluyeran de él instituciones como el Servicio Médico Nacional de Empleados

LABRA (2004) 213

LABra (2004) 214

Molina Bustos, Carlos Antonio (2006). "Antecedentes del Servicio Nacional de Salud. Historia de debates y contradicciones. Chile 1932-1952". Cuadernos Médico Sociales. Vol. 46, 4, pp., 284-304. [Disponible en línea: www.colegiomedico.cl Fecha de visita 28 de febrero de 2009] p. 286.

Molina (2006) 286.

Labra (2004) 207-219.

Molina Bustos, Carlos Antonio (2006). "La ley de Medicina Curativa. Un análisis histórico de sus antecedentes y efectos en la institucionalidad sanitaria en Chile". Cuadernos Médico Sociales. Vol. 46, 1, pp. 74-100. [Disponible en línea: www.colegiomedico.cl Fecha de visita 28 de febrero de 2009] p. 77. 
"que tenía a su cargo la aplicación de la Ley 6.154 de Medicina Preventiva, a los demás imponentes de las demás Cajas de Previsión y el Servicio Médico de la Caja de Accidentes del Trabajo" 30 , es decir, a los empleados públicos y particulares. Este factor, sumado al desfinanciamiento crónico del Servicio Nacional de Salud, impidió que este jugara el rol que su modelo inspirador -el SNS británico- jugó en la consolidación de un sistema de cobertura universal de protección de la salud.

La situación anterior devino en una suerte de 'balcanización' de los sistemas de protección de la salud chilenos. Así, por ejemplo, buena parte de los empleados -que, como mencionamos más arriba, estaban excluidos de la cobertura que entregaba el SNS- plantearon reivindicaciones corporativas en este plano, fundamentalmente a través de la presión para obtener el establecimiento de una normativa especial de salud para ellos. En virtud de lo anterior, el presidente Jorge Alessandri propuso al Congreso un proyecto de ley referido a la atención médica de los empleados. En su exposición de los fundamentos de la nueva norma legal, planteó lo siguiente:

"Consideramos que es un deber del Estado el velar porque este problema [atención médica] sea solucionado. La legislación provisional que rige en nuestro pais desde hace más de cuarenta años, si bien contempla numerosos beneficios para sus afiliados, solo establece atención médica para los indigentes, para el sector asalariado y sus familiares. Queda al margen de estos beneficios un sector importante y en pleno crecimiento, el de los Empleados Públicos y Particulares los que junto a sus familiares alcanzan hoy a un número aproximado de 1.500 .000 personas"31.

Como se advierte de lo sostenido por Alessandri, la estrategia perseguida -en lugar de avanzar hacia un sistema universal- consolidaba la fragmentación de los sistemas de salud pública, estableciendo uno para la clase media y media-alta (los empleados públicos y particulares) y otro distinto para los sectores populares. La discusión legislativa eventualmente llevó a la aprobación de la Ley No 16.701, de Medicina Curativa, que otorgaba asistencia médica y dental a los empleados públicos y particulares, dándoles además la libertad para elegir "al profesional que habrá de atenderlo, como también el hospital o clínica, para lo cual requiere que el profesional esté inscrito en el Sistema de Libre Elección del Colegio Respectivo y que el Establecimiento haya celebrado convenio con el Servicio Médico Nacional de Empleados"32.

Molina Bustos (2006) 88. El SERMENA fue creado a partir de la Ley de Medicina Preventiva, № 6.154 .
} 


\section{(1.2.3) Modificación y ampliación (Estatuto de Garantías)}

Como vimos en la sección anterior, el desarrollo del derecho a la salud durante el período 1925-1960 fue legislativo y administrativo, pero no constitucional. Sin embargo, hacia finales de la década del sesenta, se comenzó a plantear la necesidad de revisar el Texto Constitucional, de manera de caracterizar mejor el derecho a la salud en el mismo, ya que se pensaba que la forma en que se consagraban los derechos económicosociales en la Constitución de 1925 (incluido el derecho a la salud) era obsoleta. Estas inquietudes, sin embargo, solo se tradujeron en una iniciativa concreta a propósito de la elección presidencial de 1970, cuando se planteó la necesidad de modificar y reestructurar los derechos garantizados por la Constitución, especialmente los derechos sociales, como el derecho a la salud.

La coyuntura en que ello ocurrió no pudo ser más peculiar. Como es sabido, Salvador Allende no obtuvo la mayoría electoral que exigía la Constitución de 1925 para poder declararlo e investirlo como Presidente de la República inmediatamente después de la elección, por lo que -siguiendo el procedimiento previsto en la Carta de 1925- le correspondió al Congreso Pleno elegir entre las dos más altas mayorías relativas. En vista de lo anterior, y dado que los partidos que formaban la coalición política de Allende no tenían los votos suficientes, decidieron negociar con la Democracia Cristiana a fin de que los votos de sus parlamentarios apoyaran al candidato de la Unidad Popular. La Democracia Cristiana supeditó su apoyo a Allende en el Congreso a que este firmara un documento en que garantizaba formalmente que el nuevo gobierno respetaría las instituciones consagradas en la Constitución. Luego de intensas negociaciones, se concluyó un pacto político de reforma que finalmente se transformó en la Ley de Reforma Constitucional No 17.398, de enero 9 de 1971.

Esta reforma, denominada 'Estatuto de Garantías Constitucionales', introdujo una serie de modificaciones en el articulado de la Carta de 1925, particularmente en aquellas materias relacionadas con la libertad política, la libertad de expresión, el derecho de reunión, los partidos políticos, la libertad de movimiento, el derecho a la privacidad de las comunicaciones y el régimen de los medios de comunicación. Más relevante para el presente trabajo, es que ella también consideró una importante modificación al contenido y forma en que se encontraban establecidos los derechos sociales en la Constitución de $1925^{33}$. En lo que respecta al 
derecho a la salud, sin embargo, la modificación no fue sustancial, puesto que lo único que se hizo fue trasladar el inciso final del número 14 del artículo 10 original e incorporarlo como inciso final de! nuevo numeral 16 del artículo 10. Adicionalmente, se sustituyó la expresión "servicio nacional de salubridad" que contenía este inciso, por "servicio nacional de salud", es decir, solo fue un cambio de posición y de palabras, sin desarrollar o profundizar más ${ }^{34}$. En conclusión, se puede decir que la reforma constitucional de 1970 tuvo un impacto mínimo en el derecho a la salud.

\section{(1.2.4) El derecho a la salud en el gobierno de la Unidad Popular}

Los partidos políticos que integraban la Unidad Popular plasmaron en un texto el programa que seguiría Salvador Allende si era elegido para la primera magistratura del país. En ese programa se proponían medidas y acciones que debería realizar el gobierno para "terminar con el dominio de los imperialistas, de los monopolios, de la oligarquía terrateniente e iniciar la construcción del socialismo en Chile" 35 . En lo que respecta al derecho a la salud, el plan establecía como diagnóstico que "Medio millón de familias carecen de viviendas y otras tantas o mas viven en pésimas condiciones en cuanto a alcantarillado, agua potable y salubridad" 36 , además de "la necesidad de la población en materia de educación y salud son insuficientemente atendidas" 37 .

En vista de lo anterior, la Unidad Popular -en el apartado del programa titulado "Tareas Sociales"- se propuso satisfacer "estos justos anhelos del pueblo, que en verdad constituyen derechos que la sociedad debe reconocerle", lo que en salud entrañaba "Asegurar la atención médica y dental, preventiva y curativa a todos los chilenos, financiada por el Esta-

Artículo $10 \mathrm{~N}^{\circ} 16$, Constitución Política de la República 1925, "El Estado adoptará todas las medidas que tiendan a la satisfacción de los derechos sociales, económicos y culturales necesarios para el libre desenvolvimiento de la personalidad y de la dignidad humanas, para la protección integral de la colectividad y para propender a una equitativa redistribución de la renta nacional. La Ley deberá cubrir, especialmente, los riesgos de pérdida, suspensión o disminución involuntaria de la capacidad de trabajo individual, muerte del jefe de familia o de cesantia involuntaria, asi como el derecho a la atención médica, preventiva, curativa y de rehabilitación en caso de accidente, enfermedad o maternidad y el derecho a prestaciones familiares a los jefes de hogar. El Estado mantendrá un seguro social de accidentes para asegurar el riesgo profesional de los trabajadores. Es deber del Estado velar por la salud pública y el bienestar higiénico del país. Deberá destinarse cada año una cantidad de dinero suficiente para mantener un servicio nacional de salud".

35 Programa Básico de Gobierno de la Unidad Popular. Candidatura Presidencias de Salvador Allende, $48 \mathrm{pp}$.

36 Programa Básico de Gobierno de la Unidad Popular. Candidatura Presidencias de Salvador Allende, p. 8.

37 Programa Básico de Gobierno de la Unidad Popular. Candidatura Presidencias de Salvador Allende, p. 8. 
do, los patrones y las instituciones de Previsión. Se incorporará la población a la tarea de proteger la salud pública" 38 .

Dado que los cambios introducidos por el "Estatuto de Garantías" a la Carta de 1925 fueron bastante menores en lo que respecta al derecho a la salud (y siguiendo el criterio vigente de regulación o complementación legal de los derechos consagrados por la Constitución) ${ }^{39}$, el gobierno de Salvador Allende se abocó en un primer momento llevar a cabo una serie de actividades y/o acciones, como las "campañas de salud", dentro de las cuales cabe mencionar el Plan Nacional de Leche o el "Tren de la Salud", que no solo fomentaban la participación de la ciudadanía, sino que también permitían cumplir con la ideas plasmadas en el programa de gobierno, esto es, incorporar a la población en la tarea de proteger y promover la salud pública.

Por otro lado, el gobierno creó instituciones como la Consejería Nacional de Emergencia en Salud y la Consejería Nacional de Desarrollo Social, que tenían como finalidad "avanzar hacia la solución de los problemas más inmediatos, directos y cotidianos de la vida de los trabajadores chilenos: un organismo actuaría sobre la realidad como Emergencia y otro que se preocuparía del bienestar Permanente" 40 . Con todo, la modificación más relevante del período fue la "democratización del S.N.S", que significaba: "1) La creación de un Consejo Local de Salud en cada establecimiento del S.N.S.; 2) La creación, en cada Área de Salud, de un Consejo Local de Área de Salud; 3) La creación, en cada establecimiento de salud, de un Consejo Paritario, de representatividad paritaria entre trabajadores de la salud y representantes de la población"41, y que enfrentó al gobierno con la Contraloría General de la República, ya que esta repartición estimó que los Consejos Locales de Salud "no pueden entenderse sino en el sentido de que (ellos) han de actuar como meros organismos asesores o consultivos, sin que, por ende, pudiera estimarse que aquellas normas permitirían desarrollar funciones de carácter ejecutivo, las que son privativas de las reparticiones públicas que deben crearse mediante ley" 42 .

La democratización de salud constituía el primer paso para plantear la creación de un Sistema Único de Salud que "agrupase en sí mismo a los distintos sistemas de salud del país (de empleados, de las Fuerzas Arma-

Programa Básico de Gobierno de la Unidad Popular. Candidatura Presidencias de Salvador Allende, p. 26.

39 Es paradojal que siendo Salvador Allende Gossens Médico, uno de los fundadores de la medicina social y un activo impulsor de reformas sociales, no haya buscado modificar el texto constitucional que regulaba el derecho a la salud en la carta de 1925, como sí lo hizo respecto de la propiedad de la Gran Minería del Cobre.

ILLANES (1993) 481.

ILLANES (1993) 485.

ILLANES (1993) 490. 
das, de las universidades, etc.) y que prestara una atención pareja a toda la sociedad chilena, sin distinción de clases" ${ }^{\prime 3}$, proyecto que no llegó a concretarse.

\section{(1.3) EL DERECHO A LA SALUD DURANTE EL RÉGIMEN MILITAR}

El análisis de la evolución del derecho a la salud durante el régimen militar está marcado por el trabajo de reforma constitucional que realizó la 'Comisión de Estudios de la Nueva Constitución' (conocida también como 'Comisión Ortúzar'), que contribuyó a la elaboración de una nueva Carta Constitucional que modificaría radicalmente la redacción de la garantía del derecho fundamental a la salud. Sin embargo, estas enmiendas no se circunscribieron única y exclusivamente al aspecto constitucional del derecho a la salud, sino que también al aspecto legal, que plasmó un derecho a la protección de la salud erigido sobre la base de un "modelo de Estado subsidiario o mínimo fundado en el principio de subsidiariedad (o mejor dicho en lectura de tal principio asilado en su dimensión negativa o pasiva), que limita la naturaleza prestacional de estos derechos, y a una limitada garantía jurisdiccional que los excluye de una justiciabilidad en proceso de amparo vía recurso de protección" 4 .

Atendido lo expuesto, en lo que sigue se describen los planteamientos que los sectores que luego apoyarían la dictadura militar tuvieron presentes con anterioridad al 11 de septiembre de 1973 en materia de salud, para luego adentrarse en la discusión que se dio respecto a este derecho en la mencionada Comisión Ortúzar y en el Ministerio de Salud. Posteriormente, se analiza la legislación dictada para concretar este derecho y, finalmente, se revisan las interpretaciones que la dogmática y la jurisprudencia han hecho de esta norma.

\section{(1.3.1) Ideas previas}

Mientras se implementaba el programa económico-social de la Unidad Popular, en el seno de algunas instituciones académicas de oposición tuvo lugar un importante debate sobre el impacto de las políticas económicas que habían sido impulsadas por los distintos gobiernos chilenos en el siglo XX. Esta discusión finalmente se tradujo en el libro conocido como "El Ladrillo". En ese texto se argumentó que las políticas promovidas por el Estado, más que incentivar la alicaída economía nacional, ha-

Zuñiga Urbina, Francisco (2008) "Jurisprudencia del Tribunal Constitucional acerca de Derechos Económicos, Sociales y Culturales". Revista de Derecho del Consejo de Defensa del Estado, $\mathrm{N}^{\circ}$ 20, diciembre, pp., 83-109. [Disponible en línea: www.cde.cl Fecha de visita, 7 de octubre de 2009], p. 85 
bían "inhibido el ritmo del desarrollo de nuestra economía, condenando a los grupos más desvalidos de la población a un exiguo crecimiento en su nivel de vida, ya que dicho crecimiento, al no poder ser alimentado por una alta tasa de desarrollo del ingreso nacional, debía, por fuerza, basarse en una redistribución del ingreso que encontraba las naturales resistencias de los grupos altos y medios" 45 .

En materia de salud, los autores de "El Ladrillo" plantearon que el sistema de salud existente en el país, esto es, el Servicio Nacional de Salud y el SERMENA, eran ineficientes en la utilización de los recursos que obtenían, toda vez que "De los ingresos totales de la Seguridad Social se destina, aproximadamente, un $10 \%$ para medicina social, porcentaje reducido si se considera que del ingreso total que corresponde al Servicio Nacional de Salud, organismo que es el que recibe la mayor parte de este ingreso, un $40 \%$ se gasta en administración, sin que dentro de este porcentaje se incluyan las remuneraciones de médicos y profesionales" 46 .

Ante este panorama, y con el propósito de resolver los problemas de la salud pública, en el 'El Ladrillo' se plantearon tres propuestas de transformaciones que se suponía aliviaría la situación sanitaria del país. Estas eran: 1) la descentralización de la salud, permitiendo la participación y el control de la base social sobre el sistema hospitalario; 2) una nueva política de financiamiento, en donde se debía, por un lado, utilizar los recursos del Estado para subsidiar los gastos de la población de menores ingresos y, por el otro, cobrar el costo de las prestaciones de salud a quienes estaban en condiciones de pagarlo; 3) la creación de un organismo descentralizado que captara los fondos para financiamiento de la salud, de modo que se asegurara la elegibilidad de parte los usuarios de los servicios médicos. Estas ideas tuvieron una pronta acogida una vez que las Fuerzas Armadas se tomaron el poder, generando importantes debates en ámbitos gremiales, gubernamentales y constituyentes.

\section{(1.3.2) El derecho a la salud en la discusión de la nueva Constitución}

\section{(a) Comisión de Estudios de la Nueva Constitución}

La discusión respecto del derecho a la salud se realizó en varias sesiones de la Comisión Ortúzar ${ }^{47}$. La primera vez que esta lo analizó, fue en

El Ladrillo: Bases de la Politica Económica del Gobierno Militar. 193 pp. En http://www. memoriachilena.cl/temas/documento_detalle.asp?id=MC0032306. [Fecha de visita 22 de julio 2009], p. 19

46 El Ladrillo: Bases de la Política Económica del Gobierno Militar, 124.

47 Actas Oficiales de la Comisión Constituyente, sesiones 187, 190, 192, 193 y 194. Disponible en www.minsegpres.gob.cl [Fecha de visita 22 de julio de 2009].
} 
la sesión del 10 de marzo de $1976^{48}$, en que se discutió una propuesta de redacción del reconocimiento al derecho a la salud que había sido formulada en 1973 por el entonces ministro de Salud, coronel de Aviación Alberto Spoerer. Los comisionados expresaron que la indicación formulada por Spoerer era más bien una declaración de principios que articulaba lo que se estimaba deseable respecto a este derecho, y no un precepto constitucional acabado.

Luego de esta primera incursión en el tópico, el debate de la Comisión se centró en el rol que cabía al Estado en materia de salud. En las palabras de uno de los comisionados más activos en este debate. Alejandro Silva Bascuñán, "es este un punto bastante sustancial, en el que no sabe si conviene o no que la Constitución tome partido muy decididamente respecto de una materia que está todavía abierta a la discusión" ${ }^{4}$.

En la misma sesión, el comisionado Evans planteó que el derecho a la salud debía garantizar "primero, el derecho a la salud y el libre acceso a ella; segundo, la obligación del Estado de asumir plenamente la autoridad de la salud para crear las estructuras adecuadas que aseguren el cumplimiento de las prestaciones que la ley señala en un sistema nacional orgánico y, finalmente, el encargo del Estado de que vele porque las prestaciones de salud de los organismo de seguridad social sean efectivamente realizadas" 50 . En relación a este punto, Silva Bascunán efectuó una defensa de la medicina social y del aporte que ella había hecho a la sanidad e higiene del país y su población, señalando que respecto de ellas "solo cabe fortificarlos y estimularlos". En este sentido, es interesante destacar cómo este último minimizó el rol que cabía al reconocer al 'principio de subsidiariedad' en este ámbito: "esta subsidiariedad en materia de salud es menos viva, porque los valores sociales que pone en movimiento la salud son tan importantes que no pueden ser entregados al esfuerzo absolutamente libre y espontáneo de los particulares de manera que se pusiera en peligro los valores colectivos en materia de salud"51.

La defensa del tradicional sistema nacional de salud efectuada por Evans y Silva Bascuñán fue contrarrestada por las opiniones del presidente de la Comisión, Enrique Ortúzar, quien expresó su disconformidad con que se permitiera "la socialización total de la medicina", y por el

48 Actas Oficiales de la Comisión Constituyente, Sesión 187.

49 Actas Oficiales de la Comisión Constituyente, Sesión 187, p. 3. De acuerdo a lo que se expuso en esta sesión, así como lo que se menciona por parte de los funcionarios del Ministerio de Salud que concurrieron a la Comisión en la sesión 190, en el gobierno de la época existían dos visiones contrapuestas respecto del rol del Estado en materia de salud. Por un lado, estaban los que estimaban que la solución de los problemas en salud estaba en la reestructuración de los distintos servicios y, por el otro lado, aquellos que creían que los trastornos se resolverían mediante la privatización de la salud.

50 Actas Oficiales de la Comisión Constituxente, Sesión 187, p. 5.

51 Actas Oficiales de la Comisión Constituyente, Sesión 187, p. 6. 
comisionado Jaime Guzmán, quien señaló que observaba "cierta analogía entre el derecho a la salud y el derecho a la educación" 52 , ya que entendía que estos eran derechos de corte social, a los cuales el ciudadano aspira y que por lo tanto están supeditados a que el Estado sea capaz de sustentarlos desde un punto de vista económico, lo cual no siempre es posible, ya que la capacidad financiera del Estado es limitada. A continuación, Jaime Guzmán propuso que se invitara a la Comisión a especialistas en el tema, a fin de que aclararan y explicaran ciertos conceptos respecto del derecho a la salud. Ello ocurrió en la sesión del 17 de marzo de $1976^{53}$, esta vez escuchando a los especialistas del Ministerio de Salud, decanos de las escuelas de Medicina y al Director de Servicio Nacional de Salud.

La reunión se inició con la exposición del ministro de Salud de la época, Fernando Matthei, quien señaló que "en materia de salud la idea del gobierno -expresada en documentos del señor presidente- es que el Estado tiene el deber de velar por la salud de todos los chilenos y mantener un control técnico en este campo" 54 . Esta opinión fue compartida por los funcionarios del Ministerio de Salud que lo acompañaron, así como por los decanos de las facultades de Medicina invitados, Pizza y Casanegra. Reaccionando a estas intervenciones, Guzmán planteó que a su juicio existían tres problemas a considerar. El primero, era el contenido del derecho a la salud, y en este punto su idea era "tratar de redactar en la forma más exacta posible, desde el punto de vista técnico, y más sucinta, como lo exige la Constitución, cuál es el verdadero contenido preciso del derecho que se está consagrando con el nombre genérico de derecho a la salud" 55 . En segundo término, si las prestaciones o acciones que tiendan a proteger la salud debían ser realizadas gratuitamente o no. En este punto planteó la siguiente interrogante: "¿Tiene toda persona derecho a que los mecanismos que el hombre ha descubierto para proteger la salud, para rehabilitarla, reafirmarla, etcétera, le sean conferidos en forma gratuita? ¿O eso depende la capacidad económica del interesado?" 56 . Finalmente, la relación Estado-particulares en el ámbito de la salud. Al respecto, Guzmán reiteró la analogía del derecho a la salud con la libertad de enseñanza, haciendo una férrea defensa del principio de subsidiariedad respecto al derecho a la salud: "es obligación del Estado suplir todo aquello que los particulares no puedan hacer en esta materia" 57 .

La posición de Jaime Guzmán suscitó el inmediato rechazo del ministro Matthei y del director del Servicio Nacional de Salud, Merino. Este

Actas Oficiales de la Comisión Constituyente, Sesión 187, p. 7.

Actas Oficiales de la Comisión Constituyente, Sesión 190.

Actas Oficiales de la Comisión Constituyente, Sesión 190, p. 3

Actas Oficiales de la Comisión Constituyente, Sesión 190, p. 12

Actas Oficiales de la Comisión Constituyente, Sesión 190, p. 13.

Actas Oficiales de la Comisión Constituyente, Sesión 190, p. 13. 
último fue especialmente directo en su crítica a los criterios expuestos por Guzmán respecto del rol subsidiario del Estado en materia de salud, señalando que "Las autoridades de salud piensan que el Estado no puede de modo alguno, desde ningún punto de vista, delegar la responsabilidad que tiene con respecto de la salud"58. Más adelante, en la sesión del 17 de marzo de 1976, la Comisión solicitó que el Ministerio de Salud enviara una propuesta de redacción de una garantía constitucional de protección de la salud. Este lo hizo, y su propuesta sirvió de punto de partida para su trabajo discutir el derecho a la salud.

A partir de lo descrito más arriba, podemos colegir que el tratamiento del derecho a la salud en la Comisión de Estudios de la Nueva Constitución estuvo marcado por la discusión entre los comisionados que respaldaban la posición de los especialistas del Ministerio de Salud respecto del activo papel que debía desarrollar el Estado en materia de salud, y los comisionados liderados por Jaime Guzmán, que favorecían el 'principio de subsidiariedad'. No obstante esta disparidad de criterios, finalmente el asunto terminó sin resolución conclusiva, es decir, obviándose.

\section{(b) Discusión al interior del Consejo de Estado}

Como se sabe, una vez terminado el trabajo de la Comisión Ortúzar el debate acerca de la nueva constitución prosiguió en el Consejo de Estado $^{59}$. Sin embargo, en lo que respecta al derecho a la salud, la discusión fue muy limitada. Lo más relevante ocurrió a propósito de la explicación que Ortúzar hizo respecto del derecho a la salud y el rol del Estado, ya que en su intervención mencionó que la protección de la salud se llevaría a cabo por medio de instituciones públicas o privadas, respetando el 'principio de subsidiariedad' 60 . Como se advierte, Ortúzar omitió exponer al Consejo de Estado que en el seno de la Comisión que él había presidido había existido un fuerte desacuerdo entre sus miembros respecto de la importancia del principio de subsidiariedad en el ámbito de la salud.

\section{(1.3.3) El derecho a la salud en el Ministerio de Salud y las asocia- ciones gremiales}

Como explicábamos previamente, las ideas, concepciones y visiones acerca del derecho a la salud, su reconocimiento constitucional, su even-

59 El Consejo de Estado es una institución creada por el Acta Constitucional $N^{\circ} 1$, Decreto Ley $\mathrm{N}^{\circ} 1.319$ de 9 de enero de 1976. Este Consejo tenía por función principal la de ser un órgano consultivo para asuntos de gobierno y administración civil. 
tual justiciabilidad y el rol que le cabe al Estado respecto del mismo no fueron temas pacíficos en las instituciones y comisiones que tuvieron que analizarlo. Para el ámbito cercano al Ministerio de Salud, los gremios y los usuarios, las dificultades que presentaba el sistema de salud nacional eran fundamentalmente la poca claridad que existía respecto del papel que debía desempeñar el sector público, privado y mixto en provisión de servicios de salud; la reorganización del sector público de salud; la determinación de las prioridades en atención de salud; los recursos asignados a la salud; la formación de los médicos y del personal paramédico; y el papel que le corresponde a la universidades y otras instituciones de educación en esta labor ${ }^{61}$. En todo caso, el grueso de los expertos en salud estaban de acuerdo en "que el sistema adecuado para Chile era uno mixto con predominio estatal, el cual coexistía en estrecha relación con los sectores público y privado" 62 .

En una primera etapa del régimen militar (septiembre a diciembre de $1973)^{63}$, la intervención en materia de salud se había circunscrito a "normalizar" los servicios prestadores de salud, expresión que para algunos implicaba reanudar el funcionamiento de los servicios de salud, y para otros despolitizarlos o bien "adecuar el sistema de salud al nuevo modelo económico-social que se perfila" 64 . En la etapa siguiente -primeros meses de 1974 y hasta mediados de 1975-, la nueva directiva impuesta por la dictadura militar en el gremio médico manifestó una fuerte crítica a la estructura del sistema de salud existente en el país, atacando particularmente el S.N.S. y manifestando su disponibilidad a construir un sistema de salud "entregado a la economía social del mercado". Si bien existía consenso respecto de la reestructuración del S.N.S. y transformarlo en el Sistema Nacional de Servicios de Salud (S.N.S.S.), también habían discrepancias, las que no fueron oídas por las autoridades de salud, puesto que en el ańo 1975 entraron en vigencia los Decretos No 913 y No 265 "que definen la estructura del Ministerio de Salud y los lineamientos generales y específicos a que deberá ceñirse este en la puesta en marcha del S.N.S.S." y que "plantean generalizar la libre elección de salud en todo el sistema" 65 .

La radicalidad de estos cambios llevó a algunos médicos a expresar su disconformidad con las propuestas ideadas por el Ministerio de Salud y avaladas por la directiva del Colegio Médico. Esas críticas fueron contes-

Raczynski, Dagmar (1983) "Reformas al Sector Salud: Diálogos y debates". Colección Estudios CIEPLAN. 10 junio, pp. 5-44. Disponible en www.cieplan.org [Fecha de visita 25 de agosto de 2009], p. 10.

En este punto seguimos la clasificación que realiza RACZYNSKI (1983) 5-44.

RACZYNSKI (1983) 12.

RACZYNSKI (1983) 13. 
tadas por los economistas del anterior, que incluso "argumentan en contra de los aranceles profesionales (representan una práctica monopólica cuya erradicación hará posible un mayor acceso de la población a la medicina privada) y el SNS que 'no puede seguir siendo una vergüenza nacional' y a favor de un reemplazo del sistema vigente en el cual el Estado financia, administra y ejecuta los servicios de salud, por uno en que cada particular recibe recursos del Estado y puede optar por el lugar de atención que desea"66.

Una tercera etapa, que se inicia a mediados de 1975 y concluye a fines de 1976, empieza con la elección de un nuevo directorio del Colegio Médico, el cual comenzó una serie de acercamientos con el gobierno, con la finalidad de persuadir a la autoridad de salud respecto de las ideas que debía comprender la reforma a la salud en marcha. La autoridad, pausadamente, disminuyó la intensidad de la orientación "social de mercado" reconociendo que "el sistema chileno debe ser uno mixto mayoritariamente estatal en el cual hay una complementación, y no competencia, entre los servicios de salud públicos, privados y mixtos, y que al Estado le corresponde un papel activo en la salud no solo en lo normativo, sino también en lo financiero y de entrega de prestaciones de salud"67.

Este cambio de visión se profundizó aún más con la llegada ai Ministerio del general de la Fuerza Aérea, Fernando Matthei, quien expresó directamente y a través del subsecretario de la cartera que "En otros sectores de la actividad nacional (industria, comercio, servicios no vitales, etc.), el Estado puede esperar y observar si la iniciativa privada abarca o no determinadas actividades necesarias, para luego asumirlas si no son estas adecuadamente realizadas. En salud, por estar vidas en juego, y ser las acciones de salud responsabilidad y deber preferente del Estado, este no puede dejarlas descubiertas a la espera de que otros organismos las asuman. Debe cumplirlas al máximo de su capacidad y entregarlas solo cuando las actividad privada o de otros entes sociales garanticen su ejecución"68.

Desde principios de 1977 hasta mediados de 1978, comienza una cuarta etapa, que estuvo marcada por la reivindicación económica por parte de los médicos. El accionar del Colegio en esta materia se asentaba en que el gobierno, a través del ministro de Salud, había acogido "sus" planes e ideas en materia de reforma al sistema de salud, y desechando por tanto las propuestas de los asesores económicos del Ministerio.

La última etapa, que va desde mediados de 1978 a fines de 1980. En ella, el Ministerio de Salud comenzó expresando que la autoridad estaba "en vísperas de tomar decisiones a fondo sobre la Ley de Medicina $\mathrm{Cu}$ -

\footnotetext{
66 RACZYNSKI (1983) 14.

67 RACZYNSKI (1983) 16 - 17.

68 RACZYNSKI (1983) 17.
} 
rativa así como la reestructuración del sector salud"69. Ellas finalmente se materializaron, no obstante la fuerte oposición del Colegio Médico y otros organismos gremiales, mediante el DL No 2.575, que modificó la Ley de Medicina Curativa (ampliando la libre elección de Medicina Curativa sobre la base de un bono compensador, entre otras reformas), y a través del DL No 2.763, que reorganizó el Ministerio de Salud y fusionó el S.N.S. y el SERMENA, creando los Servicios de Salud, el Fondo Nacional de Salud (FONASA), el Instituto de Salud Pública (ISP) y la Central Nacional de Abastecimientos (CENABAST), "organismos estatales, funcionalmente descentralizados, con personería jurídica y patrimonio propio" 70 .

\section{(1.3.4) El derecho a la protección de la salud en la Constitución de 1980}

Una vez promulgada la Constitución de 1980, el derecho a la salud quedó incorporado en el número 9 del artículo 19. Lo novedoso de la redacción de la nueva norma constitucional fue la inclusión del derecho a elegir el sistema de salud, que además se encuentra protegido por el recurso de protección (uno de los instrumentos jurídico-constitucionales incorporados por la Carta del ochenta).

En todo caso, desde la entrada en vigencia de la Constitución de 1980 y hasta su última gran reforma (la del ańo 2005) ${ }^{71}$, ninguna de las más de cien modificaciones que ha sufrido el Texto Constitucional alcanzó al derecho a la protección de la salud, manteniéndose su redacción original.

\section{(1.3.5) La legislación en salud 1980-1990}

La entrada en vigencia de la Constitución de 1980 consagró en sede constitucional un derecho a la salud (a la protección de la salud), cuya regulación legal se sustentaba hasta entonces en los principios de la economía de mercado.

Este enfoque de la salud (ahora "amparado" por la nueva Constitución) permitió que se profundizaran las reformas estructurales al sistema de salud creado a partir del DL No 2.763. Es así como en 1980 (por DFL 1-3063, DL 3.477 y el DL 3.529), comenzó el proceso de municipalización de la salud, que implicó el traspaso de la administración de los consultorios a los municipios, proceso que se profundizó en el siguiente ańo.

Ley 20.050 del 26 de agosto de 2005. 
En efecto, en 1981 -junto con la municipalización de la salud-el gobierno dictó el DL No 3.626 y el DFL No 3, que crearon las Instituciones de Salud Previsional (ISAPRE). Estas normas "(permitieron) la libertad de elección para el trabajador dependiente para optar a comprar su seguro obligatorio de salud, ya sea del sistema público (FONASA) o del recién creado sistema privado (ISAPRE). Para estos efectos se establece una cotización obligatoria del $4 \%$ del ingreso imponible del trabajador, porcentaje que aumentó hasta llegar, en 1986, al actual 7\% del ingreso imponible, con un tope máximo de 4,2 UF mensuales" ${ }^{72}$, y cuya fiscalización era resorte del FONASA.

Posteriormente, en 1985, el Gobierno Militar, promulgó la Ley No 18.469, que "regula el ejercicio del derecho constitucional a la protección de la salud y crea un régimen de prestaciones de salud". Esta ley se limitó a repetir lo expresado por el constituyente en el número 9 del artículo 19 de la Constitución, garantizando en su artículo segundo que el "Sistema Nacional de Servicios de Salud no podrán negar atención a quienes la requieran, ni condicionarla al pago previo de las tarifas, o aranceles fijados a este efecto"73. Asimismo, creó un "régimen de prestaciones de salud".

Finalmente, para terminar con esta revisión de las regulaciones legales relacionadas con el derecho a la protección de la salud, resulta relevante mencionar la Ley No 18.933, que creó la Superintendencia de ISAPRE y modificó la legislación que regulaba a estas entidades. Esta ley fue dictada en las postrimerías del régimen militar (9 de marzo de 1990) y por su intermedio se intentó dificultar una eventual reforma del sistema privado de salud por parte del gobierno entrante.

\section{(1.4) Política SANitaria AL RETORNO A LA DEMOCRACIA 1990-2009}

La regulación legislativa del derecho a la salud desde el retorno a la democracia puede dividirse en dos periodos bastante definidos. El primero, desde 1990 hasta la elección del año 2000, en donde se intentó mejorar la situación financiera del sistema sanitario existente. El segundo, desde ese año y hasta nuestros días, caracterizado por la propuesta, discusión e implementación de una reforma integral del sistema sanitario, el denominado 'Plan AUGE' (Plan de Acceso Universal de Garantías Explícitas).

\footnotetext{
72 Aedo I., Claudio (2001) "Las Reformas en la Salud en Chile". En Larraín B., Felipe y Vergara M., Rodrigo (editores): La Transformación Económica de Chile. $2^{a}$ edición. Santiago: Productora Gráfica Andros, Santa Elena 1955, pp. 605-640. Disponible en www.cepchile. cl. [Fecha de visita 9 de marzo de 2009], p. 608. 


\section{(1.4.1) El sistema sanitario al retorno de la democracia}

La oposición al régimen militar -reunida al alero de centros de estudios y otras entidades- criticó severamente las reformas de salud que habían sido implementadas por el anterior, tanto por la base ideológica a partir de la cual se elaboraron las mismas, como por el hecho de que estas modificaciones, al ser impuestas por la autoridad sin mayor discusión y en un momento económico difícil "deterior(aron) el acceso de la población de ingresos medios y bajos a la atención de salud"74. Asimismo, se criticaba la falta de regulación del sistema privado de salud, que se había traducido en la creación por parte de las ISAPRE de miles de versiones de contratos de seguros de salud, los cuales exhibían todas las deficiencias que suelen generar arreglos de tipo mercantil en áreas no reguladas y en donde una de las partes tiene mayor poder de negociación. Este diagnóstico fue aceptado por las nuevas autoridades que asumieron el gobierno. Sin embargo, las reformas o modificaciones que el sistema de salud requería quedaron suspendidas por "la falta de un proyecto político común de salud de la Concertación"75, así como por el andamiaje institucional creado por la Constitución de 1980, que impedía alcanzar los quórum necesarios para transformaciones al sistema de salud sin contar con el apoyo de la oposición.

En vista de lo anterior, los gobiernos de Aylwin y Frei se concentraron en fortalecer el sistema de salud, inyectando importantes sumas de dinero al presupuesto del Ministerio, las que fueron invertidas en la construcción de hospitales y consultorios, en recuperar las dotaciones captadas por la medicina privada y en nivelar, en lo posible, las remuneraciones de los trabajadores del sistema sanitario público con las del sector privado.

Si bien, como mencionamos previamente, las reformas estructurales al sistema de salud no pudieron llevarse a cabo por los primeros gobiernos de la Concertación, esto no impidió que se impulsaran algunas leyes destinadas a corregir algunos de los abusos e inequidades más notorios del sistema, como la Ley No 19.284 (de 14 de enero de 1994), que introdujo normas para la plena integración social de las personas con discapacidad, o la Ley No 19.650 (de 24 de diciembre de 1999), que perfeccionó las normas del área de la salud, regulando el cheque de garantía y el proceso de declaración de urgencia, las que, en todo caso, no cuestionaron directamente la filosofía subyacente a las disposiciones constitucionales y legales que regulan el derecho a la protección de la salud.

\footnotetext{
74 Lenz, Rony (2007) "Proceso Político de la Reforma AUGE de Salud en Chile: Algunas lecciones para América Latina. Una mirada desde la Economía Política". Serie de Estudios sociol económicos CIEPLAN, $\mathrm{N}^{\circ} 38$, junio, 40 pp. Disponible en www.cieplan.org [Fecha de visita 29 de julio de 2009], p. 6.

75 LENZ (2007) 7.
} 


\section{(1.4.2) Reforma Sanitaria Plan AUGE (2000-2009)}

El periodo que va desde la instalación en el gobierno del presidente Ricardo Lagos hasta el presente, se caracteriza fundamentalmente por el estudio, discusión e implementación de la ambiciosa reforma al sistema sanitario, denominado 'Plan AUGE' (Acceso Universal de Garantías Explícitas). Esta importante transformación tuvo su inicio durante la campańa presidencial de fines de 1999. En un hecho inédito hasta ese momento, el candidato de la Concertación, Ricardo Lagos, se comprometió en avanzar hacia una reforma de la salud en una reunión con los actores del sistema público de salud.

Una vez instalado el gobierno, Lagos encomendó a la ministra de Salud, Michelle Bachelet, que llevara adelante la reforma comprometida en la campańa. Por otro lado, a nivel interministerial formó una comisión que "como organismo técnico-político [sería] encargado de generar la propuesta de reforma"76. Las discusiones entre los distintos actores del gobierno permitieron que el presidente Lagos esbozara públicamente los lineamientos de su propuesta de salud. De entre todos los lineamientos planteados, la discusión finalmente se redujo a la propuesta del gobierno de que " $3 / 7$ de la cotización obligatoria de los afiliados a ISAPRE se destinarían a financiar un Fondo de Compensación Solidario (FCS), el cual serviría para darle sustento al mayor acceso a la salud a los beneficiarios de FONASA"77. Esta idea, que buscaba reducir la inequidad del sistema, fue sin embargo resistida por la oposición, lo que reflotó antiguas disputas acerca del rol del Estado en materia de salud y participación de los privados en la provisión de servicios de salud.

Más adelante (en enero de 2002), se nombró ministro de Salud a Osvaldo Artaza, al que se le encomendó impulsar la reforma sanitaria, que se encontraba trabada por la polémica surgida en torno a la propuesta del gobierno de redistribuir las cotizaciones de salud. A pesar de la oposición a la reforma propuesta de los gremios empresariales vinculados al sector salud, el gobierno envió los proyectos de la reforma AUGE a la consideración del Congreso para su estudio y discusión. Estos proyectos de ley eran los que creaban el Régimen de Acceso Universal con Garantías Explícitas, el de Autoridad Sanitaria, la ley que modificaba la Ley de ISAPRE, la ley de Financiamiento de la Reforma y de Chile Solidario y, por último, la Ley de Derechos y Deberes de las personas en materia de salud. Junto con la presentación de estos proyectos, el gobierno llevó a cabo dos acciones adicionales, con las cuales buscaba ganar credibilidad en la ciudadanía. En primer lugar, una agresiva campaña por medios masivos de comunica-

\footnotetext{
76 LENZ (2007) 12.

$77 \quad$ LENZ (2007) 13.
} 
ción, y en segundo término, la operación del "Plan Piloto AUGE"78. Estas acciones del gobierno fueron duramente atacadas por el Colegio Médico, a través de paros y otras movilizaciones. Sin embargo, el resultado al final fue que los objetivos propuestos por el presidente Lagos al ministro Artaza se habían cumplido.

En el año 2003, asumió la cartera de salud el Dr. Pedro García, a quien le correspondió liderar la discusión de la reforma en el Senado y la implementación del Plan AUGE. En cuanto al debate parlamentario, la cámara alta rápidamente aprobó los proyectos sobre Autoridad Sanitaria, la "Ley Corta"79 de ISAPRE y el financiamiento de la reforma. En relación con el proyecto que regulaba el Régimen de Garantías Explícitas, durante su discusión se presentaron discrepancias, sobre todo en cuanto al Fondo de Compensaciones, el cual fue finalmente eliminado del proyecto. A pesar de esta supresión, en términos generales el proyecto de reforma AUGE fue un éxito para el gobierno, puesto que el punto central de este, es decir, la creación de un sistema de garantías explícitas en salud, había logrado sortear la discusión parlamentaria con éxito.

Respecto de la ejecución, el Plan AUGE contemplaba la creación de dos subsecretarias en el Ministerio de Salud -Salud Pública y Redes Asistenciales-, que empezaron a funcionar a principios de 2005. Junto con lo anterior y, desde la óptica de las enfermedades que quedarían cubiertas con el sistema, la ley dispone un sistema de gradualidad en su implementación, el que se tradujo en que, en una primera etapa, 25 patologías quedarían garantizadas, aumentándose a 40 , posteriormente a 56 , quedando el 2010 en 80 patologías las cubiertas por el AUGE.

\section{2) DOCTRINA CONSTITUCIONAL SOBRE AL DERECHO A LA PROTEC- CIÓN DE LA SALUD}

En las secciones anteriores hemos pasado revista a la evolución constitucional y legal del derecho a la salud en Chile, sin hacer una interpretación o análisis de lo que la doctrina y la jurisprudencia plantearon en relación a esta materia.

En esta segunda parte se abordan las escasas interpretaciones que ha hecho la doctrina respecto de este derecho, así como el tratamiento del mismo hecho por la jurisprudencia. Más adelante, esbozaremos el impac-

LENZ (2007) 17.

Se llama "Ley Corta" de ISAPRE a la iniciativa generada en el Congreso Nacional producto del escándalo financiero generado por la quiebra y estafa de un grupo económico, Inverlink, el cual evidenció graves fallas en las entidades fiscalizadoras y que afectó a empresas e instituciones públicas y privadas, entre las que se encontraba la ISAPRE Vida Plena, perteneciente al grupo económico mencionado. Por esta ley se introdujeron normas que, por un lado, velaban por la salud financiera de la ISAPRE y, por otro, que protegieran a los afiliados en casos de quiebra o insolvencia. 
to de la incorporación del Derecho Internacional de los Derechos Humanos a nuestro derecho constitucional en el ámbito de la salud.

\section{(2.1) VISIÓN DE LA DOCTRINA}

Todo análisis de la interpretación que la garantía constitucional del derecho a la protección de la salud ha suscitado en la doctrina nacional debe partir por reconocer el escaso desarrollo dogmático que existe en torno a este derecho en nuestro país, con excepción de la cláusula que garantiza el derecho a escoger el sistema de salud, sobre el cual existen algunos artículos, ponencias y opiniones ${ }^{80}$.

$\mathrm{Al}$ adentrarnos en el desarrollo dogmático que realizan quienes analizan este derecho, aparece, a primera vista, que la interpretación de esta norma constitucional se basa primordialmente en el análisis de los vocablos de la cláusula constitucional respectiva, buscando su significado, siguiendo en esto al Código Civil, en el Diccionario de la Lengua Espańola (RAE). Esta labor es complementada por lo que la doctrina denomina 'el análisis de la historia fidedigna del establecimiento de la norma constitucional', que en la práctica se limita a repetir las opiniones vertidas en la Comisión Ortúzar por los comisionados, como Alejandro Silva Bascuñán y Jaime Guzmán Errázuriz, quien, como vimos más arriba, no participó en todas las sesiones en donde se trató el derecho a la salud y, cuando lo

Una importante excepción la representa el trabajo de De LoRA, Pablo y ZÚNiga FajurI, Alejandra (2009). El Derecho a la asistencia sanitaria. Un análisis desde las teorias de la justicia distributiva, Madrid: Iustel, $352 \mathrm{pp}$. Otros trabajos que se han escrito sobre el tópico que nos ocupa son: Aránguiz Hernández, Paula (2001). El derecho a la salud en la legislación chilena y comparada. Memoria de prueba. Universidad de Concepción. 202 pp.; YÁŃEZ Gruliucci, María Carolina (2001). El derecho a la protección de la salud en Chile a la luz de la doctrina y jurisprudencia nacional. Memoria de Prueba. Universidad de Talca. 174 pp.; Bulnes Aldunate, Luz (2005). "El derecho a la protección de la salud en la Constitución de 1980". Gaceta juridica. No 295, pp. 12-29; Bulnes Aldunate, Luz (2001). "El derecho a la protección de la salud en la Constitución de 1980". Actualidad Jurídica: Revista de Derecho de la Universidad del Desarrollo. Año II, No 4, pp. 131-148; Bulnes Aldunate, Luz (1988). "El derecho a la salud en los ordenamientos constitucionales chilenos". Gaceta jurídica. Año XIII, No 97, pp. 3-11; Álvarez Rojas, Sergio (1990). "Aspectos del derecho a la protección de la salud como garantía fundamental de un Estado de Derecho". Revista de Derecho Público. No 47/48, pp. 119-219; VÁsquez Márquez, José Ignacio (2005). "El Déficit Garantístico del Artículo 19 No 9 de la Constitución". XXXIV Jornadas de Derecho Público. Pontificia Universidad Católica de Chile, 25-27 de noviembre de 2004. Santiago: Editorial LexisNexis, 702 pp.; Nancuante Almonacid, Ulises y Sotomayor Klapp, Roberto (2001). Derecho de la Salud. Santiago: Editorial Jurídica ConoSur, 627 pp.; Cea Egaña, José Luis (2004). Derecho Constitucional Chileno. Derechos, Deberes y Garantías. Santiago: Ediciones Universidad Católica de Chile. Tomo II, 733 pp.; Verdugo Marinkovic, Mario; Pfeffer Urquiaga, Emilio; Nogueira Alcalá, Humberto (2002). Derecho Constitucional. Tomo I. Santiago: Editorial Jurídica de Chile, 375 pp.; Silva Bascuñán, Alejandro (2008). Tratado de Derecho Constitucional. Tomo XII. De los derechos y deberes Constitucionales. Santiago: Editorial Jurídica de Chile, 413 pp. 
hizo, expuso planteamientos más bien minoritarios y poco claros respecto a este derecho ${ }^{81}$.

\section{(2.2) JURISPRUDENCIA EMANADA DEL PODER JUDICIAL Y DEL TRIBUNAL CONSTITUCIONAL}

\section{(2.2.1) Cortes de Apelaciones y Corte Suprema}

Una de las incorporaciones relevantes a la Constitución de 1980 por parte de la Comisión de Estudios de la Nueva Constitución fue el establecimiento en la propia Carta del llamado Recurso de Protección ${ }^{82}$, el cual, como se sabe, tiene la seria limitación de que no todos los numerales del artículo 19 se encuentran protegidos por el mismo, ya que la Comisión Ortúzar estimó que "los derechos sociales son expectativas o aspiraciones, cuya materialización, a diferencia de los derechos públicos subjetivos, dependen de los recursos que tenga disponible el Estado para ello"83. Por lo tanto, el derecho a la protección de la salud no se encuentra amparado por esta acción, exceptuándose el inciso final de este numeral, que reconoce el derecho a elegir el sistema de salud, el que sí se encuentra protegido por el mismo.

La configuración constitucional del derecho a la protección de la salud-que, repetimos, es un derecho reconocido constitucionalmente pero no definido ni justiciable- llevó a que los litigantes interesados en buscar protección a su derecho a la salud fundaran sus recursos de protección en el atentado al derecho a la vida. Esta situación llevó a que los tribunales superiores desecharan tales recursos, puesto que, como lo declaró la Corte Suprema el año 1987: "un análisis de la situación determinó que no se afectaba el derecho a la vida, sino que el derecho a la salud, el cual no se encuentra protegido por el recurso de protección, denegando el recurso" ${ }^{84}$.

81 El derecho a la protección de la salud fue tratado por la Comisión de Estudios de la Nueva Constitución en las sesiones 187, 190, 192, 193 y 194. El comisionado Sr. Guzmán asistió plenamente a cuatro de ellas $(187,190$ y 194), parcialmente a una (192) y no asistió a la sesión 193.

Como se sabe, el llamado Recurso de Protección tiene su origen en una propuesta legislativa, presentada por el diputado Sergio Díez Urzúa y el senador Víctor García Garcena y creada por los profesores Jaime Navarrete Barrueto y Eduardo Soto Kloss. Este proyecto, que fue presentado en junio de 1973, finalmente, por las circunstancias que vivía el país, no fue aprobado. Una vez instalado el gobierno militar, y como consecuencia del atropello a los derechos humanos, se intentó remediar la crítica internacional por medio de la implantación de este recurso, cuestión que finalmente se materializó por medio de la dictación del DL No 1.552, más conocido como el Acta Constitucional № 2.

84 Corte Suprema. 28 de diciembre de 1987. Rol N 11.635-1987. "Sepúlveda Parías, Waldo con Subdirector del Hospital Barros Luco-Trudeau". Revista de Derecho y Jurisprudencia, tomo LXXXIV, No 3 (septiembre-diciembre), sección 5, pp. 277-284. 
Posteriormente, la Corte Suprema enmendó el rumbo, al acoger un recurso de protección interpuesto en contra del director del Hospital Base de Los Ángeles, ya que estimó que "el recurrido ha actuado en forma ilegal y arbitraria, pues de todo el sistema jurídico nacional se desprende que es deber imperativo de las autoridades públicas velar por la salud y por la vida de las personas... Además, se incurrió en una omisión ilegal y arbitraria que atenta en contra del derecho a la salud y la vida de la enferma por quien se había recurrido" 85 .

Sin embargo, en otra sentencia recaída en un recurso de protección, el máximo tribunal del país volvió a sostener en sus considerandos $6^{\circ}$ ) y $7^{\circ}$ ) que: " $6^{\circ}$ ) Que, en tales condiciones, los recursos de protección no pueden prosperar respecto de ninguno de los recurrentes, porque no se dan los presupuestos de arbitrariedad e ilegalidad que permitan su acogimiento, como se manifestó, ya que atañe a las autoridades de salud llevar a la práctica las políticas de salud diseñadas e implementadas por la Administración del Estado, acorde con los medios de que se disponga para ello y con otros parámetros que no cabe dilucidar por esta vía; 70) Que, por otra parte, la protección estatal a la salud se encuentra contemplada como garantía constitucional en el artículo 19 No 9, y de este, lo único incluido en el recurso de protección es el inciso final, referido a que cada persona tendrá el derecho a elegir el sistema de salud al que desee acogerse, sea este estatal o privado, lo que no es el caso de autos" ${ }^{16}$. Como se advierte, la jurisprudencia ha sido equívoca ${ }^{87}$.

\section{(2.2.2) Tribunal Constitucional}

Como es sabido, la Ley No 20.050 -que en el año 2005 modificó la Constitución de 1980 - estuvo centrada en eliminar los "enclaves autoritarios" más evidentes que todavía exhibía la Carta heredada de la era autori-

Corte de Apelaciones de Concepción. 20 de octubre de 2000. Rol No 326-2000. "Seguel Rebolledo, Gladys con Director del Hospital Base de Los Ángeles". Revista de Derecho y Jurisprudencia, tomo XCVII, $\mathrm{N}^{\circ} 3$ (septiembre-diciembre), sección 5, pp. 256- 259.

Corte Suprema. 9 de octubre 2001. Rol No 3599-2001. "Recurso de Protección deducido por Rojas Vera, Nayade Orietta en contra del Servicio de Salud Metropolitano Oriente". Disponible en www.poderjudicial.cl [Fecha de visita 25 de noviembre de 2009]. Considerandos $6^{\circ}$ y $7^{\circ}$.

87 Últimamente, en causa rol 8826-2009, la Corte de Apelaciones de Santiago acogió por unanimidad Recurso de Protección interpuesto por Virginia Marcell Chacón en contra del Hospital San Juan de Dios y el Servicio de Salud Metropolitano Occidente por la negativa de este establecimiento de entregar un fármaco a la recurrente fundado en que este es muy costoso. Se encuentra pendiente la apelación para ante la Corte Suprema. CoRTE DE APELAciones de Santiago. 10 de noviembre de 2009. Rol No 8826-2009. "Recurso de Protección deducido por Marcell Chacón, Virginia del Rosario en contra del Hospital San Juan de Dios y el Servicio Metropolitano Occidente". Disponible en www.poderjudicial.cl [Fecha de visita 25 de noviembre de 2009]. 
taria, como los senadores designados y la inamovilidad de los comandantes en jefe de las Fuerzas Armadas. Adicionalmente, la reforma remozó el Tribunal Constitucional de manera significativa, ampliando el número de integrantes y dotándolo de nuevas atribuciones, como el poder declarar la inaplicabilidad de un precepto legal cuya aplicación resulta contraria a la Constitución, y el de expulsar preceptos legales del ordenamiento jurídico mediante la nueva 'acción de inconstitucionalidad'88. Poco después de esta importante reforma, el Tribunal Constitucional comenzó a conocer acciones de inaplicabilidad interpuestas en contra de las ISAPRE por alzas de planes de salud. Estas acciones se sustentaban en que, de acuerdo a los afectados, las alzas "infringe(n) el derecho a la protección de la salud del artículo $19 \mathrm{~N}^{\circ} 9$ que tutela la igualdad de acceso a los sistemas de salud, al permitir el artículo 38 ter una cortapisa por coste económico a la libertad de elegir y permanecer en el plan contratado" 89.

En un hecho inédito, el Tribunal Constitucional eventualmente acogió una de las acciones de inaplicabilidad presentadas en una ya legendaria sentencia ${ }^{90}$. A propósito de este fallo, el Tribunal aprovechó de esbozar una teoría acerca de la naturaleza del derecho a la protección de la salud. Así, en el considerando Vigésimo noveno de la referida sentencia declaró que "el derecho a la protección de la salud es de índole social, involucrando conductas activas de los órganos estatales y de los particulares para materializarlo en la práctica, habida consideración que la satisfacción de tal exigencia representa un rasgo distintivo de la legitimidad sustantiva del Estado Social en la democracia constitucional contemporánea"91. Como se puede advertir, para el Tribunal Constitucional la protección de la salud ha dejado de ser un derecho-programa, como lo indicaban los miembros de la Comisión Ortúzar, pasando a ser un derecho con las mismas calidades que los "derechos públicos subjetivos".

La sentencia que comentamos generó reacciones inmediatas de instituciones académicas ligadas a los partidos de oposición, como Libertad y Desarrollo que, en un documento, criticó severamente el fallo, argumentando que "nos parece negativo que la Sentencia del Tribunal Constitucional puede sentar un precedente negativo desde diversas perspectivas. Desde el punto de vista institucional, transforma al Tribunal en un verdadero decisor de políticas públicas, lo cual puede hacerse extensible a diversas áreas de la política social, dada la interpretación -y exigi-

Esta atribución hasta antes de la reforma de 2005 a la Carta le correspondía a la Corte Suprema de Justicia.

89 ZÚNiga Urbina (2008) 91-92.

90 Tribunal Constitucional de Chile. 26 de junio de 2008. Rol N 976-07. "Requerimiento de Inaplicabilidad deducido por Peña Wasaff, Silvia respecto del artículo 38 Ter de la Ley 18.933". Disponible en: http://www.tribunalconstitucional.cl/index.php/sentencias/ download/pdf/957 [Fecha de visita 26 de agosto de 2009]. TC. Rol N ${ }^{\circ} 976-07$, p. 31.
} 
bilidad- que ha hecho de los denominados derechos económico-sociales o derechos humanos de segunda generación. Las democracias modernas entregan este tipo de decisiones - de marcado carácter redistribucionista- al Congreso, a los representantes del pueblo, bajo una serie de pesos y contrapesos, rendición de cuentas periódica, elecciones, contradictoriedad en la discusión, etc. Los ministros del Tribunal Constitucional ni siquiera pueden ser objeto de acusación constitucional. Asimismo, este tipo de sentencias generan incentivos para que frente a controversias de evidente sentido contractual puedan ser resueltas en este foro constitucional. El recurso de protección ya había sido distorsionado en este sentido, y es probable que sentencias como la comentada apunten a judicializar frente al Tribunal asuntos que no debieran serlo. El denominado control concreto que realiza el Tribunal en el análisis de los requerimientos de inaplicabilidad, lejos de entregar justicia al caso concreto, podría transformarse en una nueva instancia de justicia ordinaria, con los problemas de congestión asociados" 92 .

Más adelante, en septiembre del 2009, el Tribunal Constitucional volvió a acoger una acción de inaplicabilidad interpuesto bajo similares supuestos que el anterior, incorporando como fundamento de la sentencia todos y cada uno de los considerandos relativos a la naturaleza del derecho a la protección de la salud que hizo referencia en la sentencia de 2008.

\section{(2.3) El DERECHO INTERNACIONAL EN MATERIA DE SALUD EN EL OR- DENAMIENTO CONSTITUCIONAL CHILENO}

En 1989 la Constitución de 1980 sufrió su primera gran reforma, la que busco adecuar este texto a un régimen democrático más abierto. Entre los artículos modificados, se encuentra el artículo $5^{\circ}$ inciso 2 , segunda parte, al cual se le agregó la siguiente frase: "Es deber de los órganos del Estado respetar y promover tales derechos, garantizados por esta Constitución, así como por los tratados internacionales ratificados por Chile y que se encuentren vigentes" 93 .

Alguna parte de la doctrina entendió en un principio que esa norma de la Constitución elevaba los Tratados Internaciones sobre Derechos $\mathrm{Hu}$ manos a rango constitucional. Sin embargo, poco después comenzaron a surgir voces que sostenían que dicha teoría estaba equivocada. Posteriormente otros autores ${ }^{94}$ intentaron importar a nuestro país la noción de 'bloque de constitucionalidad' para sustentar la tesis del rango constitu-

92 Instituto Libertad y Desarrollo (2008) "Caso Isapres. Jueces: ¿Reformadores Sociales?”. Fallos Públicos. N 17, agosto de 2008, p. 5. Disponible en línea en: www.lyd.com, [fecha de visita 8 de enero de 2009], pp. 4-5.

93 Artículo 5० inciso 2, segunda parte, Constitución de 1980.

94 Especialmente Humberto Nogueira Alcalá y Salvador Mohor. 
cional de los Tratados Internacionales sobre Derecho Humanos, idea que si bien fue desechada por el Tribunal Constitucional en el ańo 200295, otro fallo reciente del mismo sugiere que la idea de 'Bloque de constitucionalidad' es ahora apoyada por la mayoría de sus integrantes ${ }^{96}$.

El debate recién anotado tiene importantes efectos respecto del derecho a la protección de la salud, ya que si se acepta que el Pacto Internacional de Derechos Económicos, Sociales y Culturales (PIDESC) tiene rango constitucional (en virtud del artículo $5^{\circ}$ inciso $2^{\circ}$ de la Carta Fundamental), entonces se podría entender que el derecho a la protección de la salud consagrado por el $\mathrm{N}^{\circ} 9$ del artículo 19 de la Constitución se vería complementado por los principios y valores presentes en el pacto mencionado, lo que transformaría su fisonomía.

\section{(2.4) CONSECUENCIAS DE LA JURISPRUDENCIA}

Tanto los fallos emitidos por las Cortes de Apelaciones, la Corte Suprema y el Tribunal Constitucional han generado en el último tiempo un proceso de reflexión y discusión en torno al derecho a la protección de la salud, la "judicialización de los seguros de salud", el rol del Estado en esta materia, etc. Estos debates han sido tan importantes que ya han abandonado los centros de pensamiento y las aulas y se han alojado en las salas de directorio de importantes compañías, así como en las oficinas del Ministerio de Salud y de la Superintendencia de Salud.

Lo más notorio de este incipiente debate es que los referidos empresarios y autoridades, lejos de analizar el fondo de los cuestionamiento que hacen los tribunales (que creen que existe una vulneración grave a un derecho reconocido y protegido por la Constitución y tratados internacionales de igual jerarquía), han hecho fuertes críticas en contra de los abogados que interponen los recursos de protección e inaplicabilidad en contra de las ISAPRE, así como de los tribunales que acogen esos recursos, ya que consideran que el actuar de unos y otros produce "incertidumbre", "pone en tela de juicio la supervivencia del sistema de aseguramiento", o bien, generan posibilidades ciertas de "eventuales alzas en los precios de los planes" 97 .

El Tribunal Constitucional afirmó en la Sentencia Rol N 346-2002: “Ninguna constitución contempla el logro automático de la jerarquía constitucional mediante un simple proceso semántico como se pretende hacer con la oración agregada al inciso 2 do de nuestra carta". Fallo citado en Aldunate Lizana, Eduardo (2008) Derechos Fundamentales. Santiago: Editorial Legal Publishing, 439 pp., p. 339.

96 Véase Sentencia Rol 1340, de 29 de septiembre de 2009.

97 La Tercera (2009). "Inconveniencia de regular sistemas de salud vía fallos judiciales". Santiago, 23 de noviembre; El Mercurio (2009), Sección Cartas al Director, Santiago, 16 de noviembre; El Mercurio (2009). "MASVIDA cuestiona últimos fallos del TC sobre Isapres". Santiago, 20 de noviembre. 
Esta visión queda claramente reflejada en el editorial del diario $\mathrm{La}$ Tercera, del lunes 23 de noviembre de este ańo, que señaló que "En los dos casos mencionados ${ }^{98}$ existen normas claras aplicables a esas situaciones, pero los tribunales han optado por dejarlas sin aplicación bajo el argumento de que el derecho a la salud prima sobre las regulaciones sectoriales que puedas afectarlas en un caso particular. Esta forma de resolver los conflictos y dificultades en la aplicación de las normas de salud -tema difícil, por la importancia que este derecho tiene para cada persona- puede hacer muy compleja la gestión pública y privada en ese ámbito" 99 .

Como se advierte de esta cita, al momento de redactarse esta nota, se desarrolla en nuestro país un fuerte debate tanto acerca de las implicancias del derecho constitucional a la protección de la salud, como del rol que debe jugar el Estado y, en particular, los tribunales de justicia, en su implementación.

\section{CONCLUSIONES}

A pesar de constituir un derecho fundamental de la más alta significancia, los orígenes y trayectoria histórica del derecho a la protección de la salud en Chile han sido escasamente estudiados. En este trabajo se ha intentado ofrecer una mirada panorámica tanto de la evolución constitucional como legal de este derecho a lo largo de los siglos XIX y XX. Este recorrido histórico permite entender lo difícil que ha resultado tradicionalmente consensuar diagnósticos comunes y construir propuestas de política pública en este campo. Adicionalmente, se advierte cómo la regulación legal del derecho a la salud ha sido la que en los hechos ha permitido los avances más significativos en materia de salud, más allá de lo que ocurría en el campo constitucional. Así, por ejemplo, el Plan AUGE ha sido el más importante hito en materia de protección de la salud de las últimas décadas, aunque decisiones judiciales recientes sugieren que tanto el Tribunal Constitucional como la judicatura ordinaria podrían jugar roles clave en este campo en el futuro.

\footnotetext{
98 Se refiere al fallo del Tribunal Constitucional ( $R$ ol N ${ }^{\circ} 1287-2009$ ) que declara inaplicable la tabla de factores del DFL $N^{\circ} 1$ del Ministerio de Salud y la sentencia de la $\mathrm{I}$. Corte de Apelaciones de Santiago (Rol N 8826-2009) que obligó, en primera instancia, al Servicio de Salud Metropolitano Occidente a que otorgara una prestación de salud.

99 La Tercera (2009). "Inconveniencia de regular sistemas de salud vía fallos judiciales". Santiago, 23 de noviembre.
} 


\section{BIBLIOGRAFÍA}

- Actas del Consejo de Estado (1978). Sesión 59, del 19 de diciembre. Disponible en línea en: www.minsegpres.gob.cl [fecha de visita 18 de agosto de 2009].

- Actas Oficiales de la Comisión Constituyente, sesiones 187, 190, 192, 193 y 194. Disponibles en línea en: www.minsegpres.gob. cl [fecha de visita 22 de julio de 2009].

- Aedo I, Claudio (2001). "Las Reformas en la Salud en Chile". En Larraín B., Felipe y Vergara M., Rodrigo (editores): La Transformación Económica de Chile, 2a edición. Santiago: Productora Gráfica Andros, Santa Elena 1955, pp. 605-640. Disponible en línea en: www.cepchile.cl [fecha de visita 9 de marzo de 2009].

- Aldunate Lizana, Eduardo (2008). Derechos Fundamentales. Santiago: Editorial Legal Publishing, 439 pp.

- Álvarez Rojas, Sergio (1990). "Aspectos del derecho a la protección de la salud como garantía fundamental de un estado de derecho". Revista de Derecho Público. No 47/48, pp. 119-219.

- Aránguiz Hernández, Paula (2001). El derecho a la salud en la legislación chilena y comparada. Memoria de prueba Universidad de Concepción. 202 pp.

- Bulnes Aldunate, Luz (1988). "El derecho a la salud en los ordenamientos constitucionales chilenos". Gaceta Jurídica. Ańo XIII, No 97, pp. 3-11.

(2001). "El derecho a la protección de la salud en la Constitución de 1980". Actualidad Jurídica: Revista de Derecho de la Universidad del Desarrollo. Ańo II, No 4, pp. 131-148.

- Bulnes Aldunate, Luz (2005). "El derecho a la protección de la salud en la Constitución de 1980". Gaceta Jurídica. No 295, pp. 12-29.

- Cea Egaña, José Luis (2004). Derecho Constitucional Chileno. Derechos, Deberes y Garantías. Santiago: Ediciones Universidad Católica de Chile. Tomo II, 733 pp.

- El Ladrillo. Bases de la Política Económica del Gobierno Militar. 193 pp. Disponible en línea en: http://www.memoriachilena.cl/temas/documento_detalle.asp?id=MC0032306 [Fecha de visita 22 de julio 2009].

- Illanes, María Angélica (1993). En nombre del Pueblo, del Estado y de la Ciencia, (...) Historia Social de la Salud Pública Chile 1880/1973. Santiago: Editado por el Colectivo de Atención Primaria, $514 \mathrm{pp}$.

- Instituto Libertad y Desarrollo (2008). "Caso Isapres. Jueces: ¿Reformadores Sociales?”. Fallos Públicos. N ${ }^{\circ}$ 17, agosto de 2008, p. 5. Disponible en línea en: www.lyd.com [fecha de visita 08 de enero de 2009]. 
- Labra, María Eliana (2004). "Medicina Social en Chile: Propuestas y debates (1920-1950)". Cuadernos Médico Sociales. Vol. 44, 4, pp. 207-219. Disponible en línea en: www.colegiomedico.cl [fecha de visita 28 de febrero de 2009].

- Lenz, Rony (2007) "Proceso Político de la Reforma AUGE de Salud en Chile: Algunas lecciones para América Latina. Una mirada desde la Economía Política”. Serie de Estudios socioleconómicos CIEPLAN, No 38, junio, 40 pp. Disponible en línea en: www.cieplan.org [fecha de visita 29 de julio de 2009].

- Miranda R., Ernesto (1990). "Descentralización y privatización del sistema de salud". Estudios Público, No 39, pp. 5-66, Disponible en línea en: www.cepchile.cl [fecha de visita 16 de julio de 2009].

- Molina Bustos, Carlos Antonio (2006). "Antecedentes del Servicio Nacional de Salud. Historia de debates y contradicciones. Chile 1932-1952". Cuadernos Médico Sociales. Vol. 46, No 4, pp. 284-304. Disponible en línea en: www.colegiomedico.cl [fecha de visita 28 de febrero de 2009].

Carlos Antonio (2006). "La ley de Medicina Curativa. Un análisis histórico de sus antecedentes y efectos en la institucionalidad sanitaria en Chile". Cuadernos Médico Sociales. Vol. 46, No 1, pp. 74-100. Disponible en línea en: www.colegiomedico.cl [fecha de visita 28 de febrero de 2009].

- Nancuante Almonacid, Ulises y Sotomayor Klapp, Roberto (2001). Derecho de la Salud. Santiago: Editorial Jurídica ConoSur, 627 pp.

- Programa Básico de Gobierno de la Unidad Popular. Candidatura Presidencial de Salvador Allende, 48 pp. Disponible en línea en: http://www.memoriachilena.cl//temas/documento_detalle. asp?id=MC0000544 [Fecha de visita 13 de marzo de 2009].

- Raczynski, Dagmar (1983). "Reformas al Sector Salud: Diálogos y debates". Colección Estudios CIEPLAN, No 10, junio, pp. 5-44. Disponible en línea en: www.cieplan.org [fecha de visita 25 de agosto de 2009].

- Silva Bascuñán, Alejandro (1997). Tratado de Derecho Constitucional. Santiago: Editorial Jurídica de Chile. T. II, 271 pp.

- (2008). Tratado de Derecho Constitucional. De los derechos y deberes constitucionales, Tomo XII. Santiago: Editorial Jurídica de Chile, 413 pp.

- VÁsquez Márquez, José Ignacio (2005). "El Déficit Garantístico del Artículo 19 no 9 de la Constitución". XXXIV Jornadas de Derecho Público, Pontificia Universidad Católica de Chile, 25-27 de noviembre de 2004. Santiago: Editorial LexisNexis, 702 pp.

- Verdugo Marinkovic, Mario y Pfeffer Urquiaga, Emilio y Nogueira Alcalá, Humberto (2002). Derecho Constitucional. Tomo I. Santiago: Editorial Jurídica de Chile, 375 pp. 
- Villegas, Beltrán (ss.cc) (2001). "La caridad y el otro como otro". Estudios Públicos, pp. 81-88. Disponible en línea en: www.cepchile.cl [fecha de visita 24 de septiembre de 2009].

- Yáñez Giuliucci, María Carolina (2001). El derecho a la protección de la salud en Chile a la luz de la doctrina y jurisprudencia nacional. Memoria de Prueba Universidad de Talca. 174 pp.

- Zúñiga Urbina, Francisco (2008). "Jurisprudencia del Tribunal Constitucional acerca de Derechos Económicos, Sociales y Culturales". Revista de Derecho del Consejo de Defensa del Estado, $\mathrm{N}^{\circ} 20$, diciembre, pp. 83-109. Disponible en línea en: www.cde.cl [fecha de visita 7 de octubre de 2009]. 